\title{
The Evolution of Cooperative Collection Development in Alabama Academic Libraries
}

\section{Sue O. Medina}

The historical poverty of Alabama's academic institutions required bold action if deficiencies in library resources were ever to be overcome. The Network of Alabama Academic Libraries has implemented a successful cooperative collection development program to strengthen resources available for graduate education and research. Recommendations resulting in the establishment of the Network are reviewed along with the conceptional decisions necessary for the implementation of the cooperative collection development program. Program funding, the formula for distribution of funds to disparate institutions, and corollary activities are discussed.

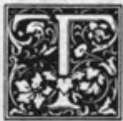

he Network of Alabama Academic Libraries (NAAL) was established in 1984 to coordinate resource sharing among the academic institutions in Alabama that offer graduate education. Its membership includes the state's coordinating body for higher education, the Alabama Commission on Higher Education (ACHE), and nineteen publicly and privately supported academic institutions. In addition, six other research and academic institutions are affiliated with the Network as cooperative members.

NAAL was created as the direct result of a 1983 report that surveyed the condition of Alabama's academic libraries and documented the deficiencies in the collective library resources needed to support graduate education and research. ${ }^{1}$ The report recommended a series of actions to overcome deficiencies identified in resources, collections, staffing, facilities, and the application of technology to library functions. Statewide cooperation and the reduction of unnecessary duplication were proposed to ensure more effective utilization of the state's limited financial resources.

Specific recommendations of the study addressed actions that would alleviate current conditions and provide a framework for establishing a resourcesharing network. One of the most important recommendations addressed the need for policies at the state level to insure that adequate collections would be developed to support any proposed new academic programs. ACHE has responsibility for approving proposed academic programs; but its 1983 criteria did not require an evaluation of available library resources. Thus, the report recommended that:

The Alabama Commission on Higher Education in cooperation with ... [the] network ... [should] develop a reasonable mechanism for reviewing library collection adequacy as part of the process of review and approval of 36104-3584. 
new academic programs. This mechanism would ensure that collections adequate to support these programs are in place or will be funded within a minimum of five years from the program's approval. ${ }^{2}$

If implemented, this recommendation would ensure adequate library resources for new programs in the curriculum. The report also recommended actions to correct deficiencies in the existing collections:

[The network should] initiate a statewide series of coordinated academic library collection analyses to identify the collection strengths and weaknesses of each academic library. The data gathered from these studies will then support the successful implementation of the following actions:

a. Eliminate existing quantitative and qualitative collection deficiencies through a multi-year retrospective collection development program.

b. Continue, and enhance, a selective retrospective conversion project so that awareness of particularly strong collections can be made available to all.

c. Develop guidelines for a statewide academic library shared collection development policy and procedure. ${ }^{3}$

Access to the collective resources was addressed in a series of recommendations calling for each institution to support membership in OCLC/SOLINET and participate in statewide resource sharing.

In 1983, the Alabama legislature appropriated $\$ 580,000$ for the NAAL. The Network was formally organized, and a plan of operation was adopted. Initial programs included statewide retrospective conversion and a statewide interlibrary loan program to address issues covered in the recommendations for the Network. Subsequent annual appropriations, reaching $\$ 1,085,513$ in 1990-91, have enabled the Network to continue these programs and add other activities, such as cooperative collection development and professional development travel grants. Table 1 lists the members, their expenditures for library materials, and monograph volumes held as of September 30, 1989.
Knowledge of specific holdings was a prerequisite to an understanding of strengths and weaknesses of the collections and a necessary foundation for resource sharing. Therefore, the Network set as its first priority the addition of bibliographic records into the OCLC/ SOLINET database. State funding for retrospective conversion of print materials began in 1984, and the last record was added in 1990. When the Network began, each institution that was not already a member joined OCLC/ SOLINET and began to catalog all current acquisitions into the database. Consequently, the Network was responsible only for retrospective conversion of materials acquired prior to $1984 .^{4}$

In the statewide resource-sharing program, NAAL members loan materials to other NAAL members on the same basis that they loan them to their own users. All charges, including photocopy costs and fees, are waived. With the assistance of HEA Title II-D, all thirty OCLC libraries in the general and cooperative member institutions received telefacsimile equipment enabling them to transmit all interlibrary loan requests that can be sent via telefacsimile. NAAL pays the basic monthly charges for the telefacsimile telephone line and funds groundbased package delivery via United Parcel Service for sending all other requests. Further, NAAL reimburses institutions for part of the cost for interlibrary loan to help cover photocopying and longdistance telephone charges for telefacsimile. ${ }^{5}$ This program helps make the collective resources of the institutions more accessible by removing geographical distance as a barrier to use.

\section{ADEQUATE COLLECTIONS TO SUPPORT NEW PROGRAMS}

One of the first actions of the new network was to create the Collection Development Committee and to charge it with implementing the recommendations of the report. The Committee's first responsibility was to work with ACHE to develop a methodology for assessing the adequacy of library collections. ACHE agreed to require the results of an assess- 
TABLE 1

NETWORK OF ALABAMA ACADEMIC LIBRARIES

\begin{tabular}{lcr}
\hline Institution & $\begin{array}{c}\text { Materials } \\
\text { Expenditures }(\$)\end{array}$ & $\begin{array}{r}\text { Volumes } \\
\text { Held }\end{array}$ \\
\hline Alabama A\&M University & 336,228 & 223,482 \\
Alabama State University & 274,024 & 175,429 \\
Auburn University & $3,341,918$ & $1,582,126$ \\
Auburn University at Montgomery & & \\
Birmingham Southern College & 340,352 & 178,537 \\
Jacksonville State University & 253,101 & 155,061 \\
Livingston University & 505,287 & 484,535 \\
Samford University & 106,680 & 96,491 \\
Spring Hill College & 624,054 & 321,476 \\
Troy State University & 123,644 & 144,299 \\
Troy State University at Dothan & 378,524 & 237,560 \\
& & \\
Tuskegee University & 124,705 & 73,658 \\
University of Alabama & 355,786 & 257,359 \\
University of Alabama at Birmingham & $2,527,176$ & $1,772,934$ \\
University of Alabama in Huntsville & & \\
University of Montevallo & $1,699,699$ & 752,705 \\
University of North Alabama & & 263,422 \\
University of South Alabama & 685,101 & 190,212 \\
U.S. Sports Academy & 184,917 & 201,689 \\
\hline
\end{tabular}

* Includes expenditures for library materials in all formats and preservation treatment such as binding

ment as part of any new program proposal submitted for approval. For this recommendation to be implemented successfully, ACHE needed a standardized assessment methodology that could be applied consistently and be acceptable to the institutions in terms of the labor required to implement it. Ideally, the methodology would also collect information useful for guiding efforts to correct identified deficiencies.

In 1985, the Network prepared guidelines, which were subsequently published, for the preparation of library assessment reports. ${ }^{6}$ The Collection Assessment Manual drew heavily on existing professional methodologies and on emerging strategies being developed for the Research Libraries Group (RLG) Conspectus. ${ }^{7}$ A series of workshops trained librarians in the specific evaluation techniques described in the Manual and in the preparation of the report for $\mathrm{ACHE}$.

Using the Manual for new program review provided the Network with an excellent test. In addition to the scheduled workshops, the Network office offered on-site training as well as assistance in interpreting data. Over the course of several years, the library faculty in all the institutions became familiar with the methodology and the report format. The assessment methodology described in the Manual could be applied consistently, the amount of work required was acceptable to the institutions, and the resulting report provided appropriate information to guide collection develop- 
ment. As a result, the Manual could be used by NAAL for a statewide collection development program.

\section{COOPERATIVE COLLECTION DEVELOPMENT}

The Collection Development Committee was also charged with developing Network guidelines for a statewide cooperative collection development program. Use of the methodology by ACHE had demonstrated that the assessment report would provide appropriate data on the following factors:

a. strength of each collection in relation to available materials;

b. strength of each collection in relation to other collections on the same subject;

c. deficiencies and gaps in coverage within each subject collection;

d. deficiencies and gaps in coverage within the statewide resources;

e. current and anticipated demands of the graduate program supported by the collection;

f. unique collections and resources;

g. institutional resources available to maintain and strengthen the collection.

Many other issues related to the statewide program had to be addressed, and the committee engaged in careful deliberation to resolve these before NAAL actually began funding collection development. First, NAAL required each member to complete conversion of its records for monographs and serials before it would be eligible for funding for collection development. This allowed the Network to implement collection development on a small scale, test its policies, and make necessary changes before all nineteen members were affected by the policies governing this facet of NAAL's activities.

Members of NAAL range from comprehensive universities offering a variety of doctoral degree and postdoctoral research programs to small liberal arts colleges offering only one master's degree program. NAAL had to be flexible in meeting these disparate needs. The Network recognized not only the neces- sity of correcting existing collection deficiencies in the individual NAAL libraries but also the need to acquire research materials for Alabama that would lie beyond the capability of any one institution. Therefore, an early premise was that at some future time, the collection development program would support two activities:

a. Instructional Support-collection development at the master's degree program level (RLG Level 3); and

b. Research Support-collection enhancement at the doctoral degree and research level (RLG Level 4).

The Network focused on implementing the instructional support activities first.

\section{INSTRUCTIONAL SUPPORT}

One of the most important debates centered on selecting subject areas that would receive NAAL funding assistance. One proposal was that NAAL identify a few academic programs, perhaps five, with special significance in terms of statewide economic development. NAAL would then fund acquisitions in these subjects for those institutions offering graduate education in those fields. Once adequacy was reached in one area, another program would be addressed. No time frame for concentrated support for each program was offered, but it was thought that this would ensure the development of adequate research collections in these subjects. Opponents argued that this approach would result in "spires of excellence on a swamp of mediocrity," and, unless the institutions could guarantee a higher level of continuing financial support, the adequacy of the selected collections would erode once NAAL support ended. After much discussion, the Committee agreed that the local institution should select the subjects needing external assistance. Rather than selecting a few subjects for special emphasis at chosen libraries, the Network would ensure that each member would receive some funds to enhance the collection of its choice.

It was also agreed that subjects receiving NAAL assistance would have to be 
linked directly to viable existing graduate education programs. Since ACHE required institutions to commit funding for adequate library resources as part of the approval of new programs, NAAL funds could not be used to develop collections for proposed or recently approved programs. Only academic programs already in the ACHE Inventory of Academic Programs would be eligible for assistance. The institutions would be required to submit information about the number of teaching faculty, number of enrolled graduate students, and number of conferred graduate degrees for each of the last three academic years. This would ensure that the programs were viable and that students and faculty would use the information resources obtained with NAAL funds.

The Network recognized ... the need to acquire research materials for Alabama that would lie beyond the capability of any one institution.

Some discussion focused on the actual ownership of materials acquired with NAAL assistance. It was agreed that these items would be the physical property of the institution but would be available to all members through interlibrary loan. Further, to help ensure timely access, the institution would add the bibliographic records to the OCLC/SOLINET database within one year of the acquisition. In the case of major microform sets, the Network required only the record of the set, not the analytics for each title in the set.

The Network readily agreed that NAAL funding could not substitute for local funding. This simple assumption ultimately led to a more detailed policy requiring that institutions maintain their level of library funding in order to be eligible for NAAL funding in all areas, collection development as well as retrospective conversion, interlibrary loan, and professional development.

Over time, questions were raised about the kinds of materials that could be acquired with NAAL funds. The Network readily agreed that unnecessary duplication should be avoided. However, if duplication of materials would relieve an interlibrary loan burden, then duplication with another institution's holdings would be allowed. An institution could not, however, use NAAL funds to acquire duplicate copies of materials it already held or to replace lost or mutilated materials. Because serials subscriptions represent a long-term financial commitment, NAAL funds could not be used to enter a new subscription. The Network agreed that backfiles of serials for which the institution maintained a current subscription could be acquired if they reduced the burden of interlibrary loan. The Network initially allowed the acquisition of music recordings to accompany scores or to demonstrate a performance, but later approved only the acquisition of print materials when faculty began to pressure librarians to acquire multimedia materials intended primarily for classroom instruction. Microform materials, while not encouraged, were considered print surrogates and were acceptable acquisitions.

Finally, the Network required each institution to present an institutional plan for collection development detailing specific actions to correct the deficiencies identified in the assessment. Occasional problems have arisen when faculty felt a NAAL allocation should be used to support current acquisitions for their personal research interests. The Network requires that librarians with responsibility for collection development in the subject being addressed control expenditures made from NAAL funds. To review the results of NAAL funding, the Network requires an extensive end-of-project report at the completion of the second year following the award of funds. This report is a full assessment, including the librarian's judgment of the beginning and existing collection level and the current collecting intensity maintained by the institution. An important use of the end-of-project report is the assurance it provides auditors that NAAL funds were spent in accordance with the insti- 
tutional plan approved by the Network. Thus, control of these expenditures remains with the library and with librarians who work within the statewide philosophy of NAAL.

Two institutions completed retrospective conversion and began NAALfunded collection development activity in fiscal year 1985-1986. Funding available for collection development was $\$ 43,000$, and it was used in three subject areas: public administration, eighteenthcentury literature, and biomedical engineering. The next year, six institutions began collection development, and nearly $\$ 136,000$ was available for twelve subjects. As more institutions began this activity, the collection development guidelines were adjusted to correct procedural problems. Most importantly, discussion centered on the development of a new formula for the distribution of NAAL funds.

\section{FUNDING COLLECTION DEVELOPMENT}

When the first priority for the Network was retrospective conversion, NAAL funds were allocated to each member on the basis of the number of volumes held when the Network began. This number ensured that each institution would receive full funding computed on the per-unit price for cataloging its retrospective records.

The retrospective conversion formula, based on the historical size of collections, provided the most money to the institution with the largest collection. For collection development, the Network sought to provide an incentive to improve institutional funding for current acquisitions. Therefore, the new formula recognized current effort rather than historical effort. Two elements decide the division of funds: expenditures for library materials and volumes added. By using expenditures as one factor, the formula recognizes the enormous cost of serials that contribute only a limited number of volumes to the volumeadded factor. Volumes added recognizes innovative collection building, such as friends-controlled endowments in which the funds are not included in the library budget or aggressive gift campaigns that result in substantial gifts to the libraries. In addition, some libraries participate in the Library of Congress gift and exchange program and, accordingly, add a significant number of materials to their collections from this source. Finally, several of the newer institutions have acquired collections from closed liberal arts colleges and are adding these volumes at a very reasonable per-volume price. These materials add a retrospective depth to the liberal arts collections of institutions established in the early 1960s. The formula recognizes these practices.

During deliberations for the new formula, the Network also examined its maintenance of effort policy. The Network realized that if NAAL funding increased substantially, no provisions had been made to encourage an institution to increase its funding for resources. The policy merely required an institution to maintain level funding for the library. Thus, the new formula included a provision that NAAL funds could not exceed 25 percent of an institution's expenditure for library materials, thus capping the amount of funds an institution could receive. The new formula also included funding for research support by setting aside 20 percent of the collection development funds for this purpose.

Implementing the new formula would result in a substantial change in grants to individual institutions. To phase in the new formula, the Network approved a two-year transition period during which each institution received a base of $\$ 7,500$; the remainder of the funds was allocated according to percentages derived from expenditures for library materials and volumes added. This ensured that no institution would suffer a sudden decrease in its allocation from NAAL. The base will be phased out by 1993-94. At that time, the 25 percent cap on NAAL funding will also be reduced to 15 percent (see appendix A).

In 1990-91, the Network allocated $\$ 835,014$ to the Cooperative Collection Development Program. Of these funds, 
80 percent are used for instructional support. The percentage of funds that each institution received was calculated using annual statistical report data submitted by each institution to the NAAL office. The largest grant made was for $\$ 140,610$ for a library expending $\$ 3,341,918$ on materials and adding 65,205 volumes. The smallest grant was for $\$ 4,388$ and was limited by the 25 percent cap. These funds are paid quarterly to the institutions. The remaining 20 percent is used for research support awards, and these grants are paid in one payment.

The depth and breadth of library resources available to the state's students, faculty, and other researchers have improved.

An analysis of subjects selected for instructional support since the collection development program began in 1985 indicates that acquisitions represent a wide spectrum of knowledge. Fears that NAAL funding would be used in a narrow range of subjects were unfounded (see graph 1). Institutions that are members of the Association of Southeastern Research Libraries have concentrated their funds in literature (emphasizing international literature) and science and technology (see graph 2). The regional public institutions' historical role as teachertraining schools is readily apparent in the 1985-91 expenditures for acquisitions supporting teacher education (see graph 3 ). The graph for the private schools is skewed by Tuskegee University, one of the first NAAL members to begin collection development, which has used its allocations in support of allied health and food science collections (see graph 4).

\section{RESEARCH SUPPORT}

The research support awards were designed as competitive grants to add new material to the aggregate of the NAAL holdings. It was anticipated that institutions would submit proposals to acquire expensive, highly specialized materials unique to the statewide resources. The projects would not represent local collection-building activities, as is the case with instructional support, but would support a research effort within the state or the institution. Acquisitions could only be made in support of RLG levelfour or -five collecting intensity. In 198990 , the first competitive awards were approved. Eight proposals were submitted by six institutions. Three were eliminated from consideration as not meeting the research support guidelines. The remaining five proposals exceeded the amount of funds available, and the Network had to decide whether to fund all five partially or to rank and fund the proposals until the funds were exhausted. The latter option was selected. Therefore, full funding was given to three proposals: Afro-American literature ( $\$ 31,648$ to Tuskegee University), eighteenth-century literature $(\$ 69,179$ to the Mervyn H. Sterne Library of the University of Alabama at Birmingham), and music ( $\$ 27,938$ to the University of Alabama). One submitting institution agreed to accept partial funding for the acquisitions of U.S. patent literature $(\$ 44,876$ to Auburn University) to support engineering resources in the state. One proposal in U.S. history, while meeting the criteria, was ranked lowest in priority and could not be funded.

The Collection Development Committee expressed concern that, with one exception, acquisitions funded through research support awards were for materials in microform. The time it takes to receive proposals, consider them in committee, and approve them in the executive council makes it difficult to use the funds for out-of-print or rare materials subject to prior sale. The Committee recognizes the problem and hopes that these grants will be used for acquisitions other than large microform sets.

The research support awards represented a significant departure for NAAL. Until these grants were made, each member benefitted directly from every NAAL program. Every NAAL institution received money for retrospective conversion; every member receives funds to support resource sharing, professional 


$$
\begin{aligned}
& \begin{array}{lllllll}
\text { G } & \text { R } & \text { A } & \text { P } & \text { H } & & 1
\end{array}
\end{aligned}
$$

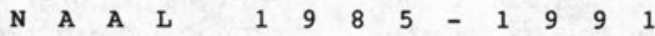

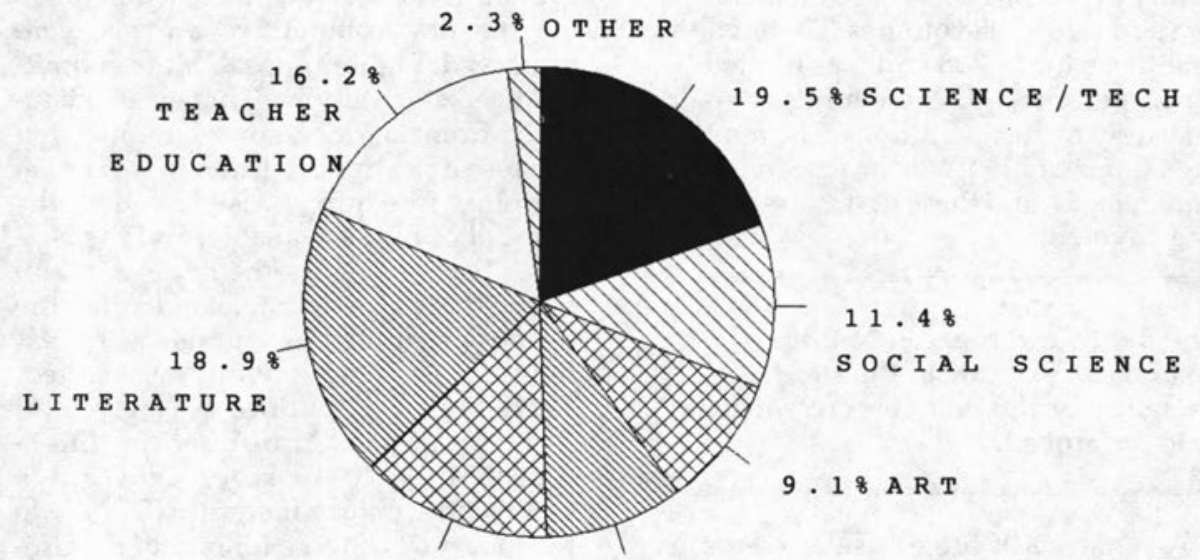

13.18

B U S I N E S S

9. 58 MED/ALLIED HEALTH $\begin{array}{lllllllll}\text { G } & \text { R } & \text { A } & \text { P } & \text { H } & & 2\end{array}$

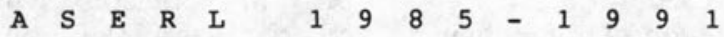

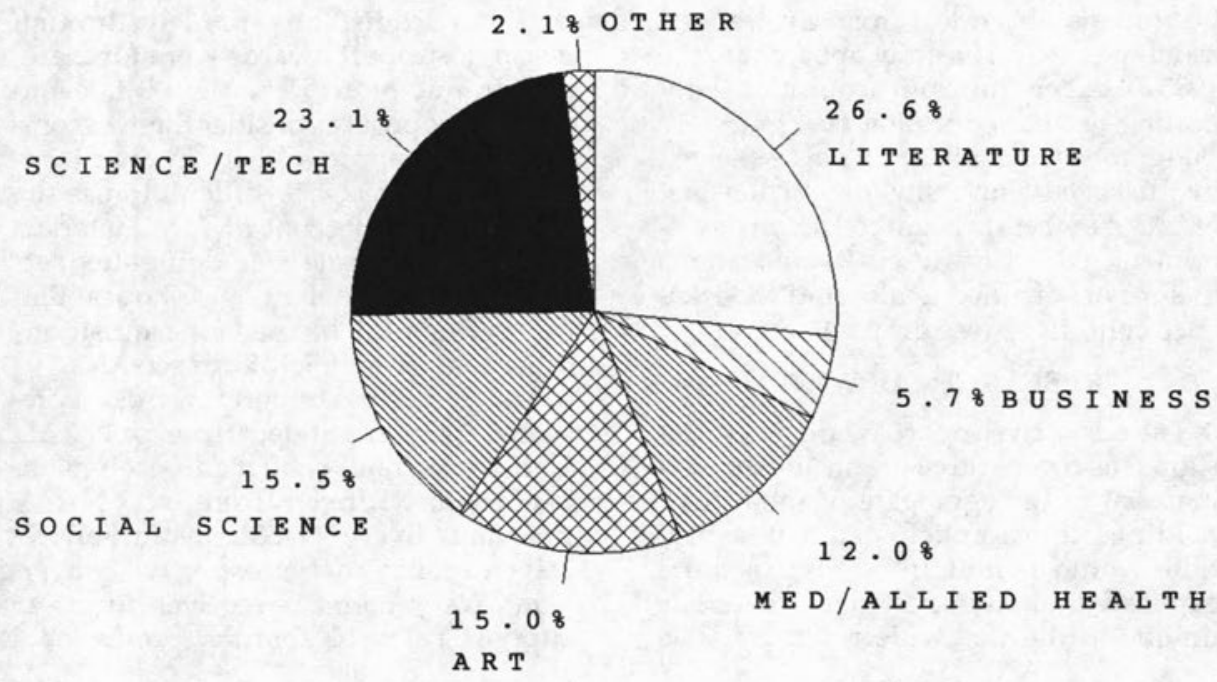

A R T 


\section{$\begin{array}{lllllllllllll}\text { G } & \text { R } & \text { A } & \text { P } & \text { H } & & 3\end{array}$}

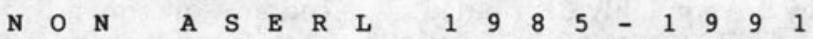

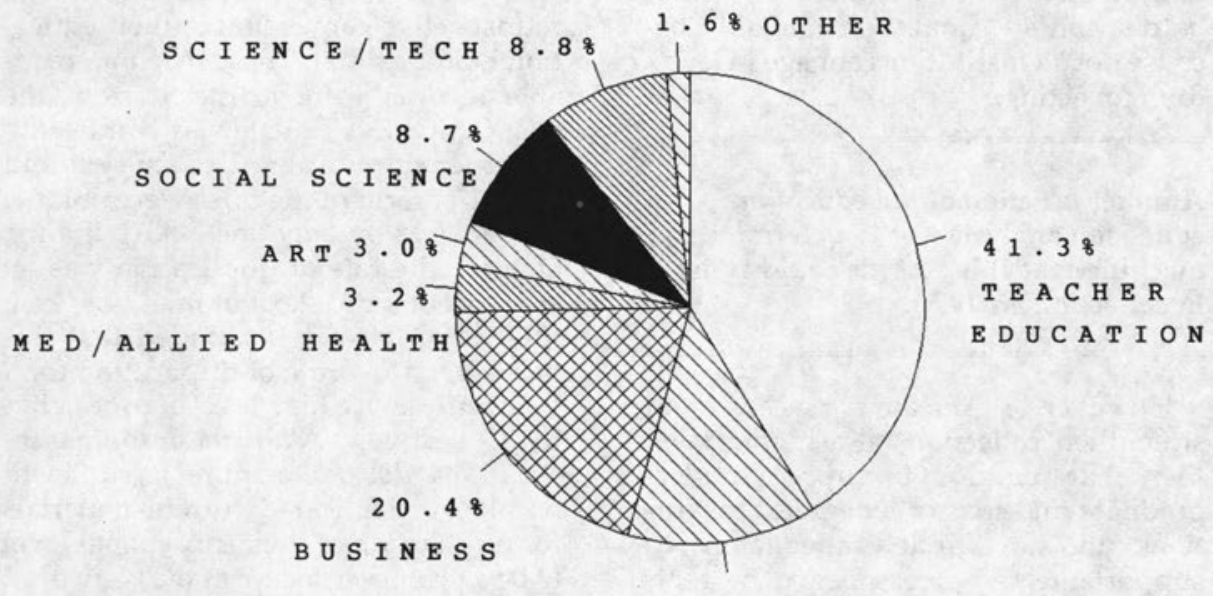

$13.0 \%$

L I T E R A T U R E

$\begin{array}{lllllll}\text { G } & \text { R } & \text { A } & \text { P } & \text { H } & 4\end{array}$

$\begin{array}{llllllllllllllll}\mathrm{P} & \mathrm{R} & \mathrm{I} & \mathrm{V} & \mathrm{A} & \mathrm{T} & \mathrm{E} & 1 & 9 & 8 & 5 & - & 1 & 9 & 9 & 1\end{array}$

$33.7 \%$

S C I E N C / T E C H

$18 \cdot 1 \%$

TE A C H E R

E D U C A T I O N

5.58 O H E R

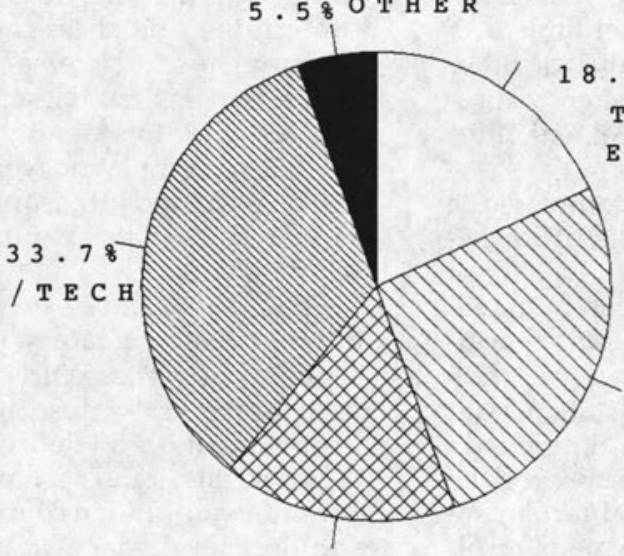

$26.5 \%$ B U S I N E S S

16.28

MED/ALLIED HEALTH 
development, and collection development. While the funds are not equally divided, they are equitably distributed, based on the level of contribution made by the institution to the statewide resources. Research support, while nominally open to any NAAL member, cannot be distributed equally or equitably because not all institutions engage in levelfour collecting.

Another function of the education collection analysis was to determine if machine-readable records could assist in collection analysis.

However, Alabama needs to strengthen collections at a higher level than that required to support undergraduate and master's degrees. Institutions are not funded adequately to support the resources needed by their undergraduate and graduate students. NAAL funding for instructional support assists every institution to meet its instructional mission for graduate education. Research support recognizes the obligation of the state to support a higher level of collecting intensity within the total resources available statewide.

\section{COROLLARY COLLECTION DEVELOPMENT ACTIVITIES}

The NAAL Cooperative Collection Development Program is not limited to the grant program. A number of other projects have been undertaken to provide better collection management information.

In 1989, the Network completed a computer-generated analysis of its collective holdings classified in the field of education. When NAAL was founded, the question of duplication was repeatedly raised: What level of duplication was being supported by the state? Could unnecessary duplication be eliminated?

Teacher education programs are the most numerous offered by NAAL members because every NAAL member offers at least one graduate degree in this field. Additionally, many students at- tend graduate-level courses to meet the requirements for ongoing teacher certification. Consequently, the Network hypothesized that the level of duplication was potentially highest in materials classified in education.

All members were asked to complete retrospective conversion of their education holdings first. These machine-readable records were extracted from the OCLC/SOLINET database and analyzed for duplication. The study found that 51 percent of the titles were unique; that is, held by only one NAAL library. Overall, the rate of duplication was an average of only 2.6 volumes for each title. The Network concluded that this was a very low rate of duplication for a field with such a high level of productivity. Collectively, Alabama academic institutions do not acquire a sufficient number of replicated current materials for duplication at the instructional level to be a primary concern of the Network. ${ }^{8}$

Another function of the education collection analysis was to determine if machine-readable records could assist in collection analysis. For the education project, the cost and time outweighed the advantages of computerized analysis. Another approach was explored with EBSCO, Inc., a serials jobber, to determine if its records could provide meaningful data on deficiencies in serials collections. The Network hypothesized that the EBSCO current serials subscriptions database could be used to identify gaps in coverage for major indexing and abstracting services. It might be possible to identify serial titles needed to complete coverage and then use NAAL funds to acquire these titles so that all the titles would be available within the state.

EBSCO undertook extensive programming to allow its data to provide an exceptions list. The Education Index was used for the test because the NAAL office had manually compiled statewide holdings for this index. Unfortunately, the variations in fund accounting at the institution level made it impossible for EBSCO to compile an accurate record of the exceptions. In addition, a number of 
libraries will pay for an employee's association membership, provided that person donates his or her serial subscription to the library. These serials do not appear in the database as current subscriptions. Both NAAL and EBSCO believed that this technique had merit and that it was unfortunate that the data were not available in the database.

Meaningful statewide collection development in Alabama must consider the large volume of material held in microform. Most large microform sets are not cataloged to the individual title level; NAAL is fortunate if the institution has the record for the set in the database. To incorporate these materials into planning for collection development, NAAL developed its Alabama Microform Project. The Network publishes Major Microform Sets Held in Alabama Libraries to identify sets held in Alabama and the indexes or other guides that make the sets more accessible. ${ }^{9}$ The Network used the first edition of the union list to acquire 250,553 set holding symbol displays on OCLC for 130,000 individual records in twenty-five sets owned by NAAL libraries for which machine-readable records were available. Each NAAL member agrees to lend its microform materials, in original or surrogate format, to other NAAL members to improve accessibility to these expensive materials. Auburn University used the Alabama Microform Project as part of its justification for HEA Title II-D funding to catalog two sets, Confederate Imprints and French Revolutionary Pamphlets, into OCLC/SOLINET. Set holding symbol displays will be acquired for other NAAL members owning these sets when the cataloging has been completed. NAAL will continue to acquire set holding symbol displays as they become available and plans to cata$\log$ analytics as funds permit.

\section{CONCLUSIONS}

The Network of Alabama Academic Libraries Cooperative Collection Development Program has provided very tangible benefits for the state of Alabama. First, and most obvious, it provides funds to increase the rate of acquisitions in selected academic programs. Students and faculty in these programs benefit by having needed research materials readily available. Strengthening an institution's collection also strengthens its contribution to the statewide resources. The depth and breadth of library resources available to the state's students, faculty, and other researchers have improved.

The librarians who participate in the NAAL Collection Development Committee have gained a wealth of knowledge related to planning for collection development.

Second, the Network has enhanced the skills of librarians responsible for collection development. The librarians who participate in the NAAL Collection Development Committee have gained a wealth of knowledge related to planning for collection development. They have analyzed the most pressing issues facing libraries and collecting policies. They have a better perspective of collections, based on their knowledge of shared resources and access. The librarians who prepare collection development proposals have markedly improved collection evaluation skills. They are better able to analyze their current collections, develop plans to correct deficiencies, provide cost data for implementation, and justify a proposal's need to the Committee and to their own administrations. As a result, Alabama is well served by a cadre of skilled collection development librarians, the peers of any such group in the nation.

Third, NAAL provides a degree of protection against the erosion of institutional support for libraries. The maintenance of effort policy requires an institution to maintain level funding for its library to be eligible for NAAL funding. Teaching faculty working with librarians to assess collections become proponents for increased funding when they discover the inadequacies of collections in their disciplines. These allies are important where competition for institutional funds is strong. 
The Network of Alabama Academic Libraries has made substantial progress in implementing a statewide cooperative collection development program that addresses the concerns raised in the 1983 study Cooperative Library Resource Sharing among Institutions Offering Graduate Education. The study broadly out- lined what was needed to improve library resources and services supporting graduate education and research in Alabama. The mechanics to achieve these improvements were left to the librarians. They have worked diligently to mold an effective program that works in a state with a long history of library neglect.

\section{REFERENCES AND NOTES}

1. Cooperative Library Resource Sharing among Universities Supporting Graduate Study in Alabama (Montgomery, Ala.: Alabama Commission on Higher Education, 1983). Eric document 224-497.

2. Ibid., p.47.

3. Ibid., p. 46-47.

4. In 1984, the Network funded retrospective conversion at $\$ 400,000$ and used a unit price of $\$ 1.27$ per record. The maximum funding in any year was $\$ 900,000$, with a unit price of $\$ 1.16$ per record. This initial project added records for print monographs and serials only. Other projects continue to add records for microforms, government publications, and materials in other formats.

5. In $1990-91$, NAAL allocated $\$ 140,500$ for the Resource Sharing Program. This includes $\$ 50,000$ to reimburse institutions for interlibrary loan services, a $\$ 35,000$ Libraries Services and Construction Act, Title III grant to reimburse NAAL for net lending to public libraries, $\$ 35,000$ for UPS, $\$ 4,500$ for telefacsimile equipment maintenance contracts, and $\$ 16,000$ for monthly telephone lines for telefacsimile. Total interlibrary loan transactions for NAAL have grown from 9,401 in $1985-86$ to 33,827 in 1989-90.

6. Sue O. Medina and others, Collection Assessment Manual (Montgomery: Network of Alabama Academic Libraries, Alabama Commission on Higher Education, 1987). ERIC Document 290-462.

7. David L. Perkins, ed., Guidelines for Collection Development (Chicago: American Library Assn., 1979), passim.

8. Fred Heath, "An Assessment of Education Holdings in Alabama Academic Libraries: A Collection Analysis Project," unpublished report to the Network of Alabama Academic Libraries, April 1990 (available from Fred Heath, c/o Mary Couts Burnett Library, Texas Christian University, P.O. Box 32904, Ft. Worth, TX 76129).

9. T. Harmon Straiton, Jr., and G. Boyd Childress, comps., Major Microform Sets Held in Alabama Libraries, AUnion List and Guide (Montgomery: Network of Alabama Academic Libraries, Alabama Commission on Higher Education, 1988). 


\section{APPENDIX A \\ THE FORMULA FOR DISTRIBUTION OF NAAL FUNDS FOR COLLECTION DEVELOPMENT}

NAAL will allocate $80 \%$ of the funds available for collection development to Instructional Support. Twenty percent ( $20 \%$ ) of the available funds will be allocated to Research Support.

The NAAL formula for the distribution of instructional support funds will:

1. allocate a base amount for each institution;

2. use the number of volumes added annually by each institution expressed as a percentage of the total added for all institutions;

3. use the annual expenditures for library materials of each institution expressed as a percentage of the total expended by all institutions;

$$
\frac{V}{T V}+\frac{E}{T E}=P
$$

$\mathrm{V}$ = volumes added by " $\mathrm{N}$ " institution

TV = volumes added by NAAL members

$\mathrm{E}=$ expenditures for library materials by " $\mathrm{N}$ " institution

$\mathrm{TE}=$ expenditures for library materials by all NAAL members and

$\mathrm{P}=$ percentage allocated to " $\mathrm{N}$ " institution

4. allocate an amount of NAAL funds that does not exceed $25 \%$ of the institution's expenditure for library materials. ${ }^{+}$

The source of data for the formula will be the annual statistical reports submitted by each institution.

* The base amount allocated to each institution was $\$ 7,500$ for the trial period, 1989-1990 and 19901991. NAAL will use the "Rule of Halves" to reduce the base beginning in 1991-1992. Thus, the base will be $\$ 3,750$ in 1991-1992 and $\$ 1,875$ in 1992-1993. There will not be a base in 1993-1994.

+ In addition, the percentage of NAAL funds in relation to the institution's expenditure for library materials will be reduced until it reaches $15 \%$ by $1993-1994$ :

Schedule of Changes

Fiscal Year

1990-1991

1991-1992

1992-1993
Base

$\$ 7,500$

3,750

1,875
$\%$

25.0

20.0

17.5 


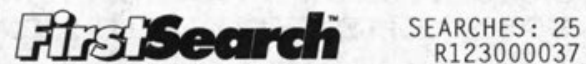 \\ EXP : 940816 \\ AUTHORIZATION : $400-030-207$ \\ PASSWORD: GRUMMAAIA \\ PHONE: (123) 456-7890 EXT:5678 \\ Risk Management}

You want to give your patrons expanded access to information by letting them search online databases. But how do you control costs?

With FirstSearch, you pay by the search, not by the minute. Patrons can search key databases like the OCLC Online Union Catalog, ERIC, The GPO Monthly Catalog, Consumers Index, plus 17 popular H. W. Wilson databases, without the risk of connect-hour charges mounting up while they search.

Give your patrons FirstSearch Cards that authorize 10 or 25 searches, and you'll have a new way to control usage. Or sell cards, if you wish, and recoup costs. You can even get a refund for searches you don't use at the end of the year.

FirstSearch eliminates the risk of hidden costs you'll discover with CD-ROM or locally mounted databases. Extra equipment, a rewired network, time lost in training staff and patrons-it adds up. Instead, FirstSearch uses your existing computer and phone line and ties directly into your local system OPAC. And our interface is so easy to understand, even novice users can start searching with no training.

Call us today for more information. With your FirstSearch, we'll change your mind about the risks of online databases for patrons.

Call your OCLC-affiliated Regional Network or OCLC Field Marketing Services and we'll send you information and an order form. 